\title{
Article \\ Evaluation of Loco-Regional Skin Toxicity Induced by an In Situ Forming Depot after a Single Subcutaneous Injection at Different Volumes and Flow Rates in Göttingen Minipigs
}

\author{
Charlotte Peloso ${ }^{1} \mathbb{D}$, Anne-Pascale Trichet ${ }^{1}$, Jacques Descotes ${ }^{2,+}$, Joël Richard ${ }^{1}$, Christophe Roberge ${ }^{1}$ \\ and Adolfo Lopez-Noriega ${ }^{1, *}$ \\ 1 MedinCell S.A., 3 rue des Frères Lumière, 34830 Jacou, France; charlotte.peloso@medincell.com (C.P.); \\ annepascale.trichet@medincell.com (A.-P.T.); joel.richard@medincell.com (J.R.); \\ christophe.roberge@medincell.com (C.R.) \\ 2 ImmunoSafe Consultance, 120 Chemin des Bouleaux, 38480 Saint-Jean-d'Avelanne, France; \\ jacques.descotes@medincell.com \\ * Correspondence: adolfo.lopeznoriega@medincell.com \\ + This article is dedicated to the memory of our dear co-worker Prof. Dr. Jacques Descotes.
}

Citation: Peloso, C.; Trichet, A.-P.; Descotes, J.; Richard, J.; Roberge, C. Lopez-Noriega, A. Evaluation of Loco-Regional Skin Toxicity Induced by an In Situ Forming Depot after a Single Subcutaneous Injection at Different Volumes and Flow Rates in Göttingen Minipigs. Int. J. Mol. Sci. 2021, 22, 9250. https://doi.org/ $10.3390 /$ ijms 22179250

Academic Editors: Bice Conti and Ida Genta

Received: 22 July 2021

Accepted: 25 August 2021

Published: 26 August 2021

Publisher's Note: MDPI stays neutra with regard to jurisdictional claims in published maps and institutional affiliations.

Copyright: (c) 2021 by the authors. Licensee MDPI, Basel, Switzerland. This article is an open access article distributed under the terms and conditions of the Creative Commons Attribution (CC BY) license (https:/ / creativecommons.org/licenses/by/ $4.0 /)$.
Abstract: The present study aims to investigate the loco-regional tolerability and injection parameters (i.e., flow rate and administration volume) of an in situ forming depot (ISFD) in Göttingen minipigs, to secure both the therapeutic procedure and compliance in chronic medical prescriptions. The ISFD BEPO $^{\circledR}$ technology (MedinCell S.A.) is investigated over 10 days, after a single subcutaneous injection of test item based on a DMSO solution of diblock and triblock polyethylene glycol-polylactic acid copolymers. Injection sites are systematically observed for macroscopic loco-regional skin reactions as well as ultrasound scanning, enabling longitudinal in vivo imaging of the depot. Observations are complemented by histopathological examinations at $72 \mathrm{~h}$ and $240 \mathrm{~h}$ post-injection. Overall, no treatment-emergent adverse effects are macroscopically or microscopically observed at the subcutaneous injection sites, for the tested injection flow rates of 1 and $8 \mathrm{~mL} / \mathrm{min}$ and volumes of 0.2 and $1 \mathrm{~mL}$. The histopathology examination confirms an expected foreign body reaction, with an intensity depending on the injected volume. The depot morphology is similar irrespective of the administration flow rates. These results indicate that the ISFD BEPO ${ }^{\circledR}$ technology can be considered safe when administered subcutaneously in Göttingen minipigs, a human-relevant animal model for subcutaneous administrations, in the tested ranges.

Keywords: loco-regional skin tolerability; in situ forming depots; subcutaneous injection; flow rate; minipig; sustained release drug delivery

\section{Introduction}

Over the past few decades, the field of smart and controlled delivery systems has been continuously expanding, investigating approaches from the nano to the macrometric scale [1] and from nondegradable implants to bioresorbable systems [2,3]. Most of these drug delivery strategies are designed to improve the bioavailability and pharmacokinetics of target therapeutic molecules, with a view to reducing dosing frequency compared to immediate release dosage forms and, consequently, improving treatment compliance [4]. Among the available formulation approaches, in situ forming depots (ISFD) are particularly attractive as they are designed to bio-resorb and are often easier to administer compared to preformed delivery systems [5]. The common feature of ISFD is the formation of a solid depot encapsulating a drug upon administration $[5,6]$. They are classified according to the solidification mechanism, i.e., in situ cross-linking [7,8], in situ solidifying organogels [9] or in situ phase separation $[10,11]$.

Despite the growing interest of the scientific community, little is known regarding the loco-regional toxicity potential of ISFD [5,12], even though this is a key development 
issue of every sustained-release injectable drug. Poorly tolerated injectable formulations (e.g., local pain, discomfort, redness) may lead to a significantly lowered observance of the treatment and its discontinuation, regardless of efficacy [13,14]. In addition, repeated administrations of the product could be compromised if sensitization induces a locoregional reaction at the injection site (e.g., itching, skin eruption). Interestingly, in addition to the biocompatibility of the formulation components, factors linked to the injection procedure are being increasingly evaluated for their influence on loco-regional tolerability, in particular, with classic aqueous-based injectable products, such as insulin or heparin. Critical factors include the type of device, the selected injection site and the injection flow rate [15-17]. Similar investigations are necessary with ISFD systems to demonstrate their safe use for the patient and understand if the injection criteria, particularly the injection flow rate, influences the formation of the depot and subsequent loco-regional tolerability $[18,19]$.

MedinCell proprietary ISFD technology [20], trademarked as BEPO ${ }^{\circledR}$, is composed of (1) a mixture of one diblock and one triblock copolymer of poly(ethylene glycol) (PEG) and amorphous poly(D,L-lactic acid) (PDLLA), (2) a biocompatible organic solvent and (3) an active pharmaceutical ingredient (API). The API may be either in solution or in suspension in the polymeric vehicle, which is designed to be water insoluble. Upon administration, the solvent will diffuse out of the system and be replaced by bodily fluids, causing the copolymers to precipitate and form a solid depot, which physically entraps the API. The therapeutic agent will be released by a combination of diffusion through the polymeric matrix and progressive degradation of the copolymers. BEPO ${ }^{\circledR}$ technology allows an unprecedented flexibility in the control of the release, which may span from days to months by tailoring its composition [21,22], such as e.g., the size of the copolymers, the solvent type or the ratio among the formulation components. This ISFD technology is currently undergoing advanced clinical trials for both systemic drug delivery using the subcutaneous (SC) route, and local delivery within the intra-articular space.

The present article depicts the results from an experimental study designed to assess the loco-regional skin tolerability of the ISFD BEPO ${ }^{\circledR}$ technology. Different volumes of a model $\mathrm{BEPO}^{\circledR}$ vehicle (copolymer mixture dissolved in solvent, without API) were administered subcutaneously to Göttingen minipigs at different flow rates. The minipig was selected as it has been shown that its SC space is similar to that of humans in terms of tissue structure and biomechanics [23,24]. The test item selected for this study was composed of hydrophobic copolymers with a relatively high molecular weight $(10-12 \mathrm{kDa})$. The resulting product with a high copolymer concentration in dimethyl sulfoxide (DMSO) was expected to reach a very high dynamic viscosity ( $>500 \mathrm{mPa} . \mathrm{s})$. This polymeric composition was designed to give relatively slow degradation kinetics, allowing a monitoring and comparison of the different reactions with minimal variations in the depot polymeric composition during the study period. Typical injection speed for a marketed product being around 3-6 mL/min (administration of $0.5 \mathrm{~mL}$ to $1 \mathrm{~mL}$ in $10 \mathrm{~s}$ ) [25], a wide range of manual injection speeds were selected, with a slow and a fast injection rate targeting $1 \mathrm{~mL} / \mathrm{min}$ and $10 \mathrm{~mL} / \mathrm{min}$. In addition to the flow rate, two volumes of test item (i.e., 0.2 and $1 \mathrm{~mL}$ ) were injected to assess a potential effect of increased depot volume on injection site tolerability [26,27] and depot morphology in the SC [28]. Loco-regional tolerability was assessed over 10 days by macroscopic observation and subsequent histopathology evaluation of the injection sites. It is assumed that intolerance due to the administration procedure would be noticeable within less than two weeks. Ultrasound imaging was used to complete the evaluation by providing information on the morphology of the depot and the surrounding tissues.

\section{Results}

\subsection{Characterization of the Test Item}

Test item characterization was performed immediately following batch preparation. Table 1 presents the viscosity values of the test item and the injection force needed at both flow rates $(n=3)$ as well as the Endotoxin level in the prepared batch. 
Table 1. Test item characterization results.

\begin{tabular}{|c|c|c|c|c|}
\hline \multirow{2}{*}{$\mathbf{H}$} & \multirow{2}{*}{ Viscosity } & \multicolumn{2}{|c|}{ Injection Force } & \multirow{2}{*}{ Endotoxin Leve } \\
\hline & & $1 \mathrm{~mL} / \mathrm{min}$ Flow Rate & $10 \mathrm{~mL} / \mathrm{min}$ Flow Rate & \\
\hline Test item & $\begin{array}{c}625 \mathrm{mPa} . \mathrm{s} \\
(5)^{*}\end{array}$ & $\begin{array}{l}2.5 \mathrm{~N} \\
(0.6) *\end{array}$ & $\begin{array}{l}19.0 \mathrm{~N} \\
(0.2)^{*}\end{array}$ & $<2.339 \mathrm{EU} / \mathrm{mL}$ \\
\hline
\end{tabular}

* Standard deviation.

In the tested shear rate range, the test item displayed a Newtonian behavior with a constant viscosity at each point measured (see Figure S1). Hence, the calculated viscosity value is the mean viscosity measured at each shear rate test time-point. The test item was confirmed to have a high viscosity, i.e., above $600 \mathrm{mPa}$.s. Regarding injectability, the difference between the injection force values at the two tested flow rates was statistically significant $(p<0.0001, n=6)$. The injection force at $1 \mathrm{~mL} / \mathrm{min}$ was of $2.5 \mathrm{~N}$ compared to $19 \mathrm{~N}$ at $10 \mathrm{~mL} / \mathrm{min}$. Both injection force values were below $20 \mathrm{~N}$, which is considered the limit for a comfortable manual administration of an injectable drug product [29]. Thus, the experimental conditions were considered appropriate for in vivo injection. In addition, endotoxin levels were measured below $2.339 \mathrm{EU} / \mathrm{mL}$ based on the highest injected volume (i.e., $1 \mathrm{~mL}$ ). This result is significantly below the determined limit and comply with the USP-calculated limit, confirming the low pyrogenic potential of the prepared product.

\subsection{In Vivo Administration of the Test Item}

Each animal received the full scheduled dose at each injection site. Injection durations were recorded and flow rates calculated according to the volume administered ( 0.2 or $1 \mathrm{~mL})$. Table 2 summarizes the mean flow rates and the corresponding deviation from the target value for each treatment group.

Table 2. Experimental injection flow rates. Deviations were calculated from the targeted injection flow rates (i.e., $1 \mathrm{~mL} / \mathrm{min}$ or $10 \mathrm{~mL} / \mathrm{min})$.

\begin{tabular}{ccccc}
\hline & \multicolumn{2}{c}{ Target 1 mL/min } & \multicolumn{2}{c}{ Target 10 mL/min } \\
\cline { 2 - 5 } & Flow Rate & Deviation & Flow Rate & Deviation \\
\hline \multirow{2}{*}{ Group 1-0.2 mL } & $1.0 \mathrm{~mL} / \mathrm{min}$ & $-2 \%$ & $5.6 \mathrm{~mL} / \mathrm{min}$ & $(1.4)^{*}$ \\
Group 2-1 mL & $(0.0)^{*}$ & & $8.0 \mathrm{~mL} / \mathrm{min}$ & $-44 \%$ \\
& $(0.0 \mathrm{~mL} / \mathrm{min}$ & $-2 \%$ & $(1.0)^{*}$ & $-20 \%$ \\
\hline
\end{tabular}

* Standard deviation.

Slow injections $(1 \mathrm{~mL} / \mathrm{min})$ were performed as planned. No deviation from the targeted injection duration was observed in any of the groups. In contrast, substantial deviations were observed for the highest flow rate $(10 \mathrm{~mL} / \mathrm{min})$. As a result, the maximum injection flow rate experimentally reached in this study was $8 \mathrm{~mL} / \mathrm{min}$.

\subsection{Macroscopic Observation of Loco-Regional Skin Tolerance}

No treatment-linked loco-regional adverse effects were observed in the animals, regardless of the test item volume and the injection flow rate. Figure 1 is a compilation of representative pictures from both injection sites for a $1 \mathrm{~mL}$-treated animal during the 10-day follow-up of the study. Representative pictures of the $0.2 \mathrm{~mL}$ treated group are presented in Figure S2. 


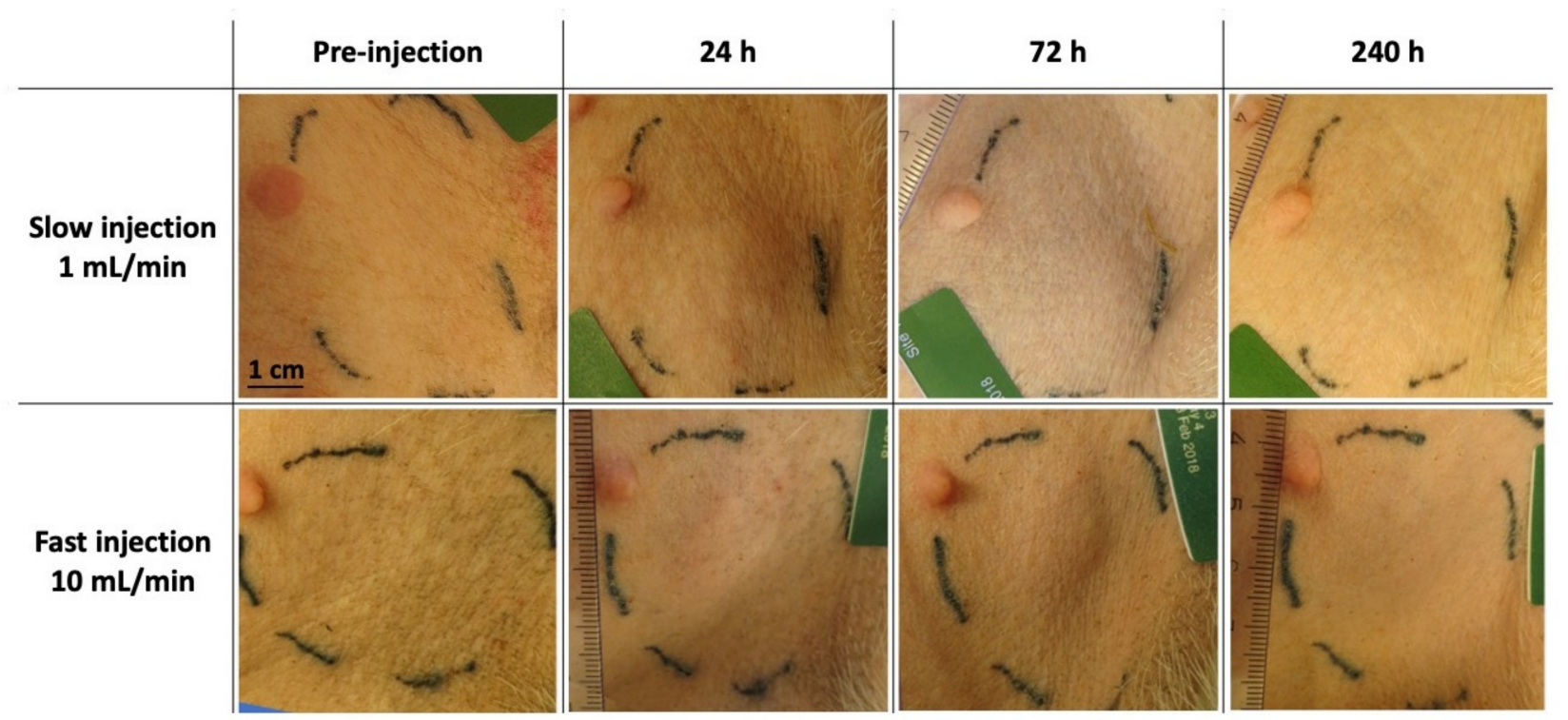

Figure 1. Macroscopic loco-regional tolerance assessment. Representative images of injection sites from $1 \mathrm{~mL}$ treated group along the study.

From $24 \mathrm{~h}$ post-injection, both groups displayed a localized induration which persisted over the 10-day observation period.

\subsection{Ultrasound Imaging}

Representative ultrasound images of the injection site from each treatment group are presented in Figure 2. The images were similar regardless of the injection flow rate. Full imaging along the sagittal and transverse planes is presented in Figure S3. The test item was confirmed as being properly injected into the subcutaneous space, except for one depot of $0.2 \mathrm{~mL}$ injected at the fast flow rate, which was partially injected intramuscularly. These data were excluded from further analysis.

A

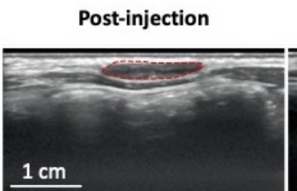

$24 \mathrm{~h}$

$48 \mathrm{~h}$

$72 \mathrm{~h}$

$144 \mathrm{~h}$

$240 \mathrm{~h}$
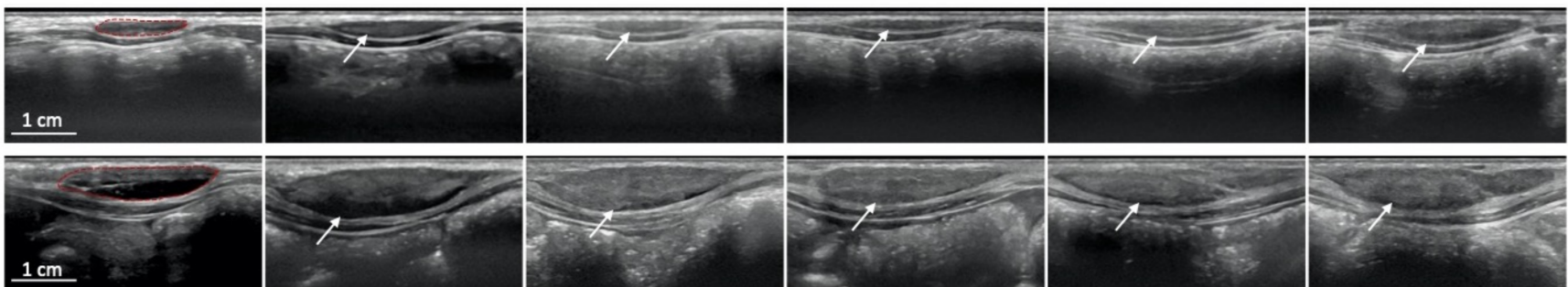

Figure 2. Longitudinal ultrasound imaging of (A) $0.2 \mathrm{~mL}$ and (B) $1 \mathrm{~mL}$ test item injection site over the course of the study. Images were acquired between 13 and $15 \mathrm{MHz}$ along the sagittal plane, parallel to the needle insertion orientation. Bolus are highlighted in red post-injection and indicated by an arrow at later time points.

For each injection, the depot is predominantly fusiform and hypoechoic immediately after injection. From $24 \mathrm{~h}$ onward, an increase in echogenicity was observed, which is characteristic of ISFD phase inverting systems [30].

Dimensions of the depot were measured from both sagittal and transverse depot images. The depot volumes at each injection site are presented in Figure 3a. With both 0.2 and $1 \mathrm{~mL}$ injection volumes, a sudden volume increase was observed at $24 \mathrm{~h}$ postinjection followed by a steady decrease down to the initial injected volume at $72 \mathrm{~h}$ postinjection. From this time point, the depots progressively expanded again. There was no 
significant difference between the measurements from the injection sites at two different injection flow rates $(p=0.9824, n=73)$.

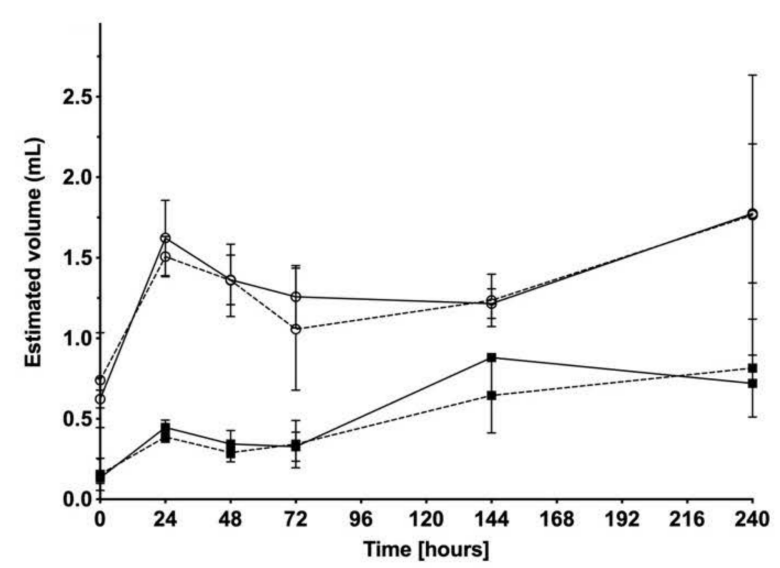

(a)

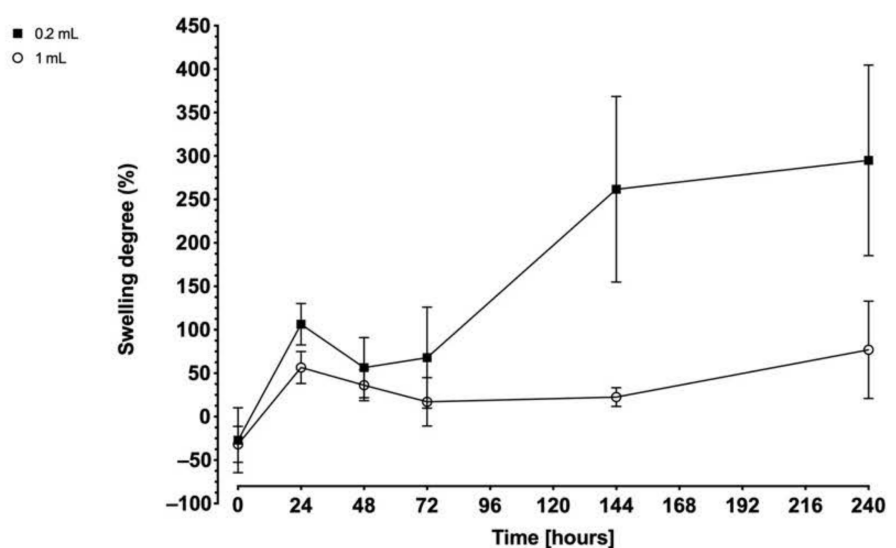

(b)

Figure 3. Variation of depot volume over the course of the study (10 days): (a) the calculated volumes from both injections are displayed at both injection sites: site 1 as full line; site 2 as dotted line; (b) the degree of depot swelling is presented for both volumes as the mean of the two injection sites.

In Figure $3 \mathrm{~b}$, depots degree of swelling is presented as the mean of both injection sites (i.e., site 1 injected at $1 \mathrm{~mL} / \mathrm{min}$ and site 2 injected at $10 \mathrm{~mL} / \mathrm{min}$ ). At $24 \mathrm{~h}$ post-injection, the mean swelling was $+106 \%$ for a $0.2 \mathrm{~mL}$ test item injection and $+57 \%$ for a $1 \mathrm{~mL}$ test item injection, representing an estimated volume of 0.4 and $1.6 \mathrm{~mL}$, respectively. Maximum swelling was recorded at $240 \mathrm{~h}$ post-injection. For the $0.2 \mathrm{~mL}$ test item injection volume, a swelling ratio of $+295 \%$ was reached corresponding to an approximate volume of $0.8 \mathrm{~mL}$, an expansion of about four times the initial volume after 10 days. In parallel, the $1 \mathrm{~mL}$ test item injection volume swelled up to approximately $1.8 \mathrm{~mL}$ (+77\% swelling degree), which is not significantly different from the $24 \mathrm{~h}$ data.

\subsection{Histopathologic Evaluation}

Injection sites were collected at either $72 \mathrm{~h}$ or $240 \mathrm{~h}$ post-injection to evaluate the short and longer-term evolution of a potential loco-regional reaction triggered by the injection procedure. The 72 - $\mathrm{h}$ time point was appropriate to observe any acute inflammatory reaction related to the injection procedure, while the 240 -h time point allowed to characterize the chronic inflammatory reaction produced by the depot.

Animals 1 and 2 (Group 1) and 5 and 6 (Group 2) were sacrificed at $72 \mathrm{~h}$ post-injection. The remaining animals were sacrificed at $240 \mathrm{~h}$. All histopathological findings were observed in the subcutis. Only one injection in animal $4(0.2 \mathrm{~mL}$ test item treatment injected at $10 \mathrm{~mL} / \mathrm{min}$ ) was partially located in the abdominal wall. As the general shape of the depot was similar to other depots, it was not excluded from the microscopic evaluation. Representative histopathology slides are compiled in Figure 4.

At $72 \mathrm{~h}$ post-injection, a "pseudocyst" was observed in the SC space of seven of the eight investigated injection sites (Figure $4 \mathrm{~A}$ ) for both 0.2 and $1 \mathrm{~mL}$ injections. The pseudocyst or inflammatory cyst was a well-circumscribed cystic space with no epithelial lining marked out by inflammatory elements such as fibrosis or inflammatory cells. The observed empty spaces presumably originated from the test item dissolution during histology processing. At $72 \mathrm{~h}$ post-injection, pseudocysts were limited by a thin fibrous capsule admixed with few inflammatory cells, mainly macrophages, and the occasional presence of multinucleated macrophages (Figure $4 \mathrm{C}$ ). In this connective tissue surrounding the cavities or the pseudocysts, various combinations of mixed inflammatory cell infiltrates, hemorrhage and/or necrosis were occasionally observed, mainly in animals that had received $1 \mathrm{~mL}$ test item injections. The severity of these changes was low (from minimal to mild). All changes 
at $72 \mathrm{~h}$ post-injection were observed independently of the injection flow rate and/or the injected volume.

At the 240-h time point, all animals had a well-defined subcutaneous encapsulated, often multilocular, nodule. This nodule was composed of empty spaces limited by fibrous cords combined with mixed inflammatory cells, among which numerous multinucleated giant macrophages were observed. Overall, these nodules are considered to be areas of granulomatous inflammation. In one instance $(0.2 \mathrm{~mL}$ test item injected slowly), chronic inflammation was observed in the surrounding connective tissue. The severity of these changes was graded as moderate for most injection sites, and as marked on one occasion.

Overall, reactions were similar in nature between animals treated with $0.2 \mathrm{~mL}$ and $1 \mathrm{~mL}$ of test item. Similarly, the rate of administration had no influence on the nature and severity of the loco-regional changes, as shown in Figure 5.

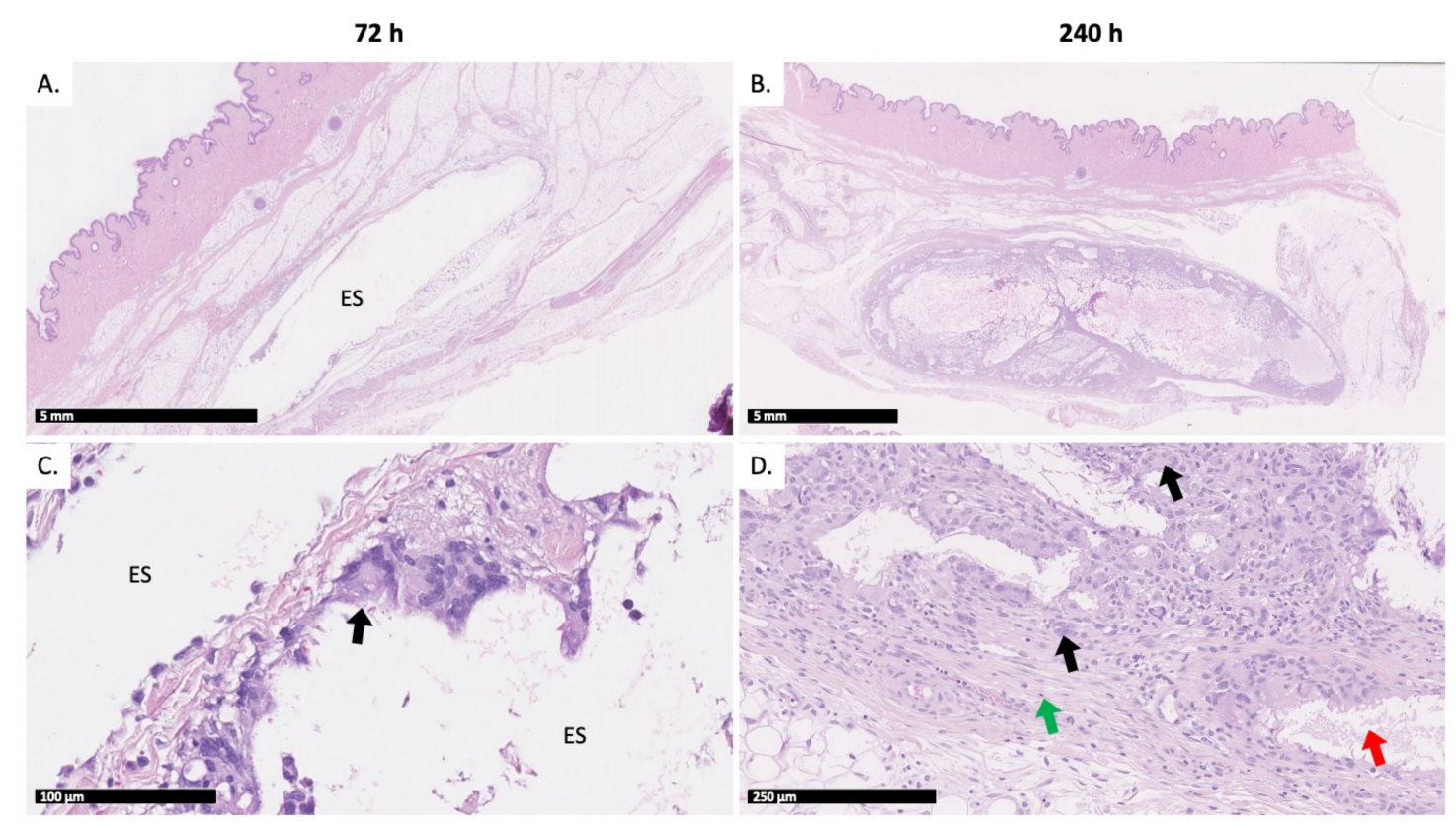

Figure 4. Representative H\&E histopathology of injection sites: (A) test item injection site at $72 \mathrm{~h}$ and (B) test item injection site at $240 \mathrm{~h}$. A focus on the fibrous capsule is presented (C) at $72 \mathrm{~h}$, and (D) at $240 \mathrm{~h}$. ES: poorly defined empty spaces in the subcutis. Green arrow: fibrous capsule. Black arrow: inflammatory cells, including multinucleated macrophages. Red arrow: empty spaces.

A.

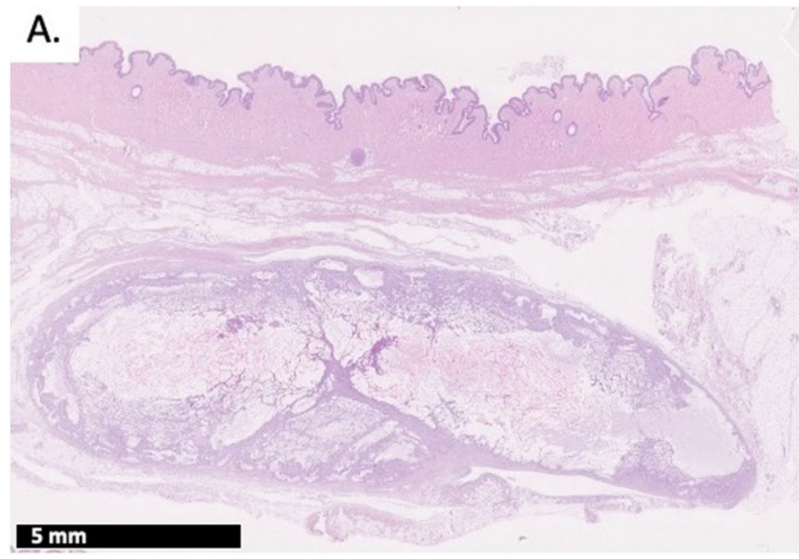

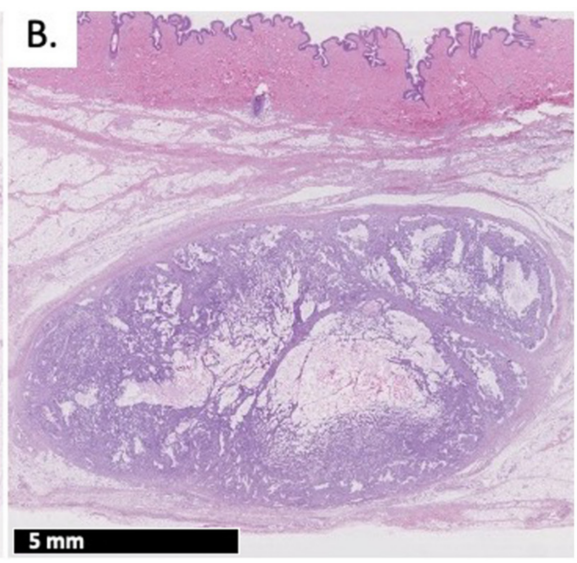

Figure 5. H\&E histopathology of $1 \mathrm{~mL}$ test item depots at $240 \mathrm{~h}$, administered at (A) slow and (B) fast injection flow rate.

Full histopathology grading is available in Table S1. 


\section{Discussion}

The ISFD BEPO ${ }^{\circledR}$ technology is based on the combination of a drug substance with an injectable vehicle solution made of a diblock and a triblock PEG-PLA copolymer solubilized in an organic solvent. This long acting injectable technology forms a solid depot in situ allowing sustained delivery of an API over several days to several months [21]. The aim of the present study was to evaluate the influence of the injection flow rate and injection volume of a $\mathrm{BEPO}^{\circledR}$ vehicle on the loco-regional skin tolerance.

Currently, little is known regarding the loco-regional tolerability of ISFD in the subcutaneous environment $[5,12]$. Due to the large variety of ISFD (i.e., different formation mechanism, applications, polymeric and solvent components, route of administration), it is difficult to generalize the available results. DMSO is an FDA-approved pharmaceutical excipient for parenteral administration, including the subcutaneous route. As for the copolymers, the tolerability of PEG-PLA copolymers has already been described in subcutaneous [31,32] and intravenous [33,34] administrations. However, data are lacking regarding their use in ISFD by phase inversion. Most published studies focus on PLGAbased ISFD [12,35-38]. Nonetheless, more than the components of the ISFD technology, the procedure to conduct a preclinical loco-regional toxicity study is not yet standardized. The few studies with PLGA ISFD using DMSO as solvent for subcutaneous administration have been conducted in a variety of species, going from monkey [39] to rat [40]. In our case, we favored the use of Göttingen minipig to assess subcutaneous reactions as this species has the closest resemblance to human subcutis [24,41]. Moreover, to the best of our knowledge, the administration procedure of ISFD has not yet been investigated. This lack of harmonized methodologies and historical data is showing the need for a tolerability study for a specific copolymer and solvent combination and its associated route and procedure of administration. In the present study, we decided to inject a highly viscous test item (>600 $\mathrm{mPa} . \mathrm{s}$ ) in the subcutaneous space of Göttingen minipigs using two different injection flow rates $(1$ and $10 \mathrm{~mL} / \mathrm{min})$ and volumes $(0.2 \mathrm{~mL}$ and $1 \mathrm{~mL})$, allowing to screen challenging parameters.

The endotoxin levels within the test item complied with the USP-calculated limit based on the highest injected volume (i.e., $1 \mathrm{~mL}$ ). This result confirmed the low pyrogenic potential of the prepared product. In parallel, the in vitro characterization of the test item demonstrated that the highest targeted injection flow rate $(10 \mathrm{~mL} / \mathrm{min})$ was consistent with an acceptable range of force required for manual injection in vivo (i.e., $<20 \mathrm{~N}$ [29]) with the selected device (i.e., $1 \mathrm{~mL}$ Luer Lock Soft-Ject syringe equipped with 21G 5/8" needle). However, by reaching the limit of a comfortable manual injection, the probability of deviation from the targeted injection flow rate was increased. To comply with a $10 \mathrm{~mL} / \mathrm{min}$ injection, the operator had to complete the administration in a short amount of time (i.e., within one second for a $0.2 \mathrm{~mL}$ injection and six seconds for a $1 \mathrm{~mL}$ injection) while being confronted with an important break-loose force. The observed deviation at $10 \mathrm{~mL} / \mathrm{h}$ for the $0.2 \mathrm{~mL}$ injection was of $-44 \%$, with injection durations ranging from 1 to $3 \mathrm{~s}$, while the one for the $1 \mathrm{~mL}$ injection was of $-20 \%$, with injections within 6 to $8 \mathrm{~s}$. Therefore, the highest manual injection rate that a well-trained operator could achieve during this animal study was up to $8 \mathrm{~mL} / \mathrm{min}$ instead of $10 \mathrm{~mL} / \mathrm{min}$.

From a macroscopic point of view, all injections were well tolerated regardless of the injection volume and flow rate. Indurations were noticed throughout the 10-day study. Because of the very thin skin and hypodermis at the plica inguinalis site, the presence of the depots was evident upon palpation, suggesting that the induration mainly resulted from the polymeric precipitate formed in the SC space. In addition, ultrasound images allowed the confirmation of the presence of a hyperechoic structure (i.e., the depot), with a volume evolving similarly to the induration recorded, supporting the observation that the local response was mainly linked to the presence of the polymeric depot.

Ultrasound imaging was performed and confirmed that the injections were properly delivered into the subcutaneous tissue. From a morphological point of view, the injected test item formed an oblate ellipsoid depot upon precipitation that stretched along the 
sagittal axis (i.e., a similar direction to needle insertion) and remained visible throughout the 10-day study. The presence of the depot at the last time point was expected because of the specific polymeric composition of the tested $\mathrm{BEPO}^{\circledR}$ vehicle. These observations also confirm the relevance of the ellipsoid volume formula to determine the depot volume. With ultrasound imaging, the injected test item was hypoechoic immediately after injection and for the first $24 \mathrm{~h}$, suggesting the presence of liquid within the depot (e.g., solvent, fluids from the tissues or mixture both). Overall, the depot morphology was similar with slow and fast injection flow rates. Qualitatively, the depot became more hyperechoic $48 \mathrm{~h}$ post-injection. According to the literature, this change in echogenicity reflects the copolymer precipitation during the depot formation [30,42,43].

Measurements of the depot dimensions along the sagittal and longitudinal plains were expected to be a direct measurement of the formed depot. Depot swelling was observed with both 0.2 and $1 \mathrm{~mL}$ injection volumes and peaked at $24 \mathrm{~h}$ and $240 \mathrm{~h}$ postinjection, regardless of the injection flow rate. Swelling is a common feature of ISFD, especially due to the water uptake upon solvent exchange [44-46]. In addition, $\mathrm{BEPO}^{\circledR}$ depots are known to often exhibit a porous internal structure [21] characteristic of a rapid solvent exchange process. Consequently, they might be prone to fluid uptake due to the more or less interconnected network of pores. Moreover, the extent and kinetics of swelling are suspected to depend on the polymeric composition of the depot, as it has previously been highlighted in works on polyester polymers [42,46]. In consequence, the first volume increase (i.e., at $24 \mathrm{~h}$ ) could be associated to the fast solvent/non-solvent phase exchange while the progressive expansion up to $240 \mathrm{~h}$ could be the result of the particular polymeric composition exploited in this study combined with a porous internal network characteristic of $\mathrm{BEPO}^{\circledR}$-based products. Interestingly, the depots formed with lower injection volumes (i.e., $0.2 \mathrm{~mL}$ ) tended to expand more than those with an injection volume of $1 \mathrm{~mL}$, proportionally to the initial volume injected. At the later time point (i.e., $240 \mathrm{~h}$ post-injection), $1 \mathrm{~mL}$ depots swelled up to 1.8 times their initial volume. In contrast, $0.2 \mathrm{~mL}$ depots swelled more with a 4 -fold increase in volume. A potential explanation for this volume-dependent swelling behavior could be that a maximum local expansion of the subcutaneous environment surrounding the depot was reached with the higher volume. This mechanical restriction would thus allow for a greater expansion of the smaller than the larger volume.

To complete this study, histopathological examination of the injection sites was performed at either $72 \mathrm{~h}$ or $240 \mathrm{~h}$ post-injection, to evaluate the short and longer-term evolution of a potential loco-regional reaction, while assessing the impact of the injection flow rate. Pseudocysts were observed at $72 \mathrm{~h}$ post-injection at both injection sites, whereas nodules were recorded at $240 \mathrm{~h}$ post-injection. In both morphological changes, empty spaces were observed: unique and large cavities in the case of pseudocysts, smaller and multilocular cavities in the case of nodules. These cavities most probably represent the location of the polymeric depots, which dissolved during tissue processing, hence their empty appearance. At early time points, only a few multinucleated macrophages were observed within the pseudocyst. Later, the cavity was gradually replaced by a mature granulomatous inflammation comprising fibrosis, inflammatory cells and many multinucleated giant macrophages. These pseudocysts and nodules represent a continuum characteristic of an expected foreign body reaction (FBR) $[47,48]$. FBR is an innate biological response taking place in two phases: (1) an acute phase for immediate injury response lasting from hours to days with blood and tissue fluid proteins accumulating around the foreign material and migration of neutrophils and (2) a chronic phase with macrophage proliferation for foreign material engulfment, creation of foreign body giant cells (FBGC), and proliferation of fibroblasts to form a fibrous capsule around the depot $[14,49,50]$. In this study, fibrosis was recorded from $72 \mathrm{~h}$ post-injection, which means that the FBR chronic phase response was already active. It can be suspected that the acute phase was initiated immediately after injection. It can also be supposed that the involved fluid accumulation in this phase accentuated the early swelling behavior observed at $24 \mathrm{~h}$. At $240 \mathrm{~h}$ post-injection, the non-negligible 
presence of multinucleated giant macrophages, i.e., FBGC, confirms that macrophages have entered a "frustrated phagocytosis" phase, as they are unable to degrade the depot individually $[47,48,51]$. This prolonged FBR was expected given the particular polymeric composition of the test item. As a matter of fact, the vehicle was designed to represent a slow degradation rate (i.e., it had a high polymeric content and copolymers with a long hydrophobic chain length).

\section{Materials and Methods}

\subsection{Materials}

Diblock mPEG-PDLLA and triblock PDLLA-PEG-PDLLA copolymers were synthesized by CM Biomaterials (Tucker, GA, USA). USP grade DMSO (Procipient ${ }^{\circledR}$ ) was purchased from Gaylord Chemical (Los Angeles, CA, USA). The diblock used in this study was composed of mPEG of $2 \mathrm{kDa}$ and PDLLA of $9.8 \mathrm{kDa}$ average molecular weight. The triblock used was composed of PEG of $1 \mathrm{kDa}$ and PDLLA of $9.8 \mathrm{kDa}$. The in vivo study was conducted by CitoxLab Scantox A/S (Lille Skensved, Denmark) in compliance with the ARRIVE guidelines [52] and EU Directive 2010/63/EU for animal experiments.

\subsection{Preparation of the Test Item}

The $\mathrm{BEPO}^{\circledR}$ vehicle was prepared by weighing the necessary amounts of TB and DB copolymers to reach a final concentration of $40 \%$ (weight/weight) in a glass vial, with a 1:1 TB:DB ratio. After addition of the proper amount of DMSO, the vial was sealed and left under agitation on a roller mixer at room temperature. Complete dissolution of the copolymers was assessed visually by obtaining a clear, translucent and viscous solution. The solution was then sterilized by filtration through a $0.2 \mu \mathrm{m}$ PTFE filter, and immediately aliquoted into sealed clear sterile vials.

For the in vivo phase, one aliquot of each test item was sent to CitoxLab Scantox A/S at $+2-8{ }^{\circ} \mathrm{C}$. Another aliquot was kept at MedinCell labs (Jacou, France) for characterization.

\subsection{Characterization of the Test Item}

\subsubsection{Dynamic Viscosity Determination}

Test item dynamic viscosity was determined using a Rheometer MCR301 (Anton Paar $\mathrm{GmbH}$, Graz, Austria) associated with a Peltier temperature system (P-PTD 200, Anton Paar GmbH, Graz, Austria) connected to the Rheocompass v1.25.422 software (Anton Paar $\mathrm{GmbH}$, Graz, Austria). The measuring system used was a Cone-Plate of $50 \mathrm{~mm}$ diameter and $1^{\circ}$ angle (CP50-1, truncation: $\left.104 \mu \mathrm{m}\right)$. Approximately $700 \mu \mathrm{L}$ of product was poured onto the Peltier plate before lowering the measuring system. Measurements were performed using a rotational method at $+25^{\circ} \mathrm{C}$. The shear rate was controlled from $10 \mathrm{~s}^{-1}$ to $1000 \mathrm{~s}^{-1}$ in a logarithmic ramp, with 10 points/decade and $5 \mathrm{~s}$ per point.

\subsubsection{Assessment of Injectability}

The injection forces required at the targeted flow rates of 1 and $10 \mathrm{~mL} / \mathrm{min}$ were determined by using a Texturometer FTPlus friction tester (Ametek STC, Berwyn, PA, USA) piloted by the NEXYGENPlus 3.0 software (Ametek STC, Berwyn, PA, USA). Flow rates were set as follows: $10 \mathrm{~mL} / \mathrm{min}$ was found to be the fastest achievable manual injection speed from tests performed by several technicians; $1 \mathrm{~mL} / \mathrm{min}$ was considered the slowest acceptable flow rate for an injection duration compliant with the animal well-being and study procedure, taking into account the volumes to be administered. Tests were performed with the same syringe, needle type and brand as those used during the in vivo administration (i.e., $1 \mathrm{~mL}$ Luer Lock Soft-Ject syringe equipped with $21 \mathrm{G} 5 / 8^{\prime \prime}$ needle). An excess of test item was filled into the syringe before locking the needle. Priming was performed by adjusting the injection volume to $500 \mu \mathrm{L}$. A compression method was used at room temperature $\left(+20^{\circ} \mathrm{C} \pm 5\right)$ with a preload stress of $0.2 \mathrm{~N}$. Test speed was calculated according to the syringe tube length, to convert the targeted flow rate from $\mathrm{mL} / \mathrm{min}$ to $\mathrm{mm} / \mathrm{min}$. The full force profile for the test item delivery at each injection flow rate was 
recorded using the pressure sensor of the Texturometer. The injection force was determined as the mean sustained force applied to the plunger to expel the test item from the device.

\subsubsection{Bacterial Endotoxins Test}

Bacterial endotoxins were dosed in the pre-clinical batch to assess the pyrogenicity of the product. Quantification was performed by Nelson Labs (Heverlee, Belgium) by dissolution of $200 \mathrm{mg}$ of product into $1 \mathrm{~mL}$ of Acetonitrile. The test article was assayed in a microtiter plate in duplicate, at a 100-fold dilution in Limulus amoebocyte lysate (LAL) reagent water. The microtiter plate was pre-incubated in a plate reader at $37 \pm 1{ }^{\circ} \mathrm{C}$ for $\geq 10 \mathrm{~min}$. After incubation, kinetic QCL-reagent $(0.1 \mathrm{~mL})$ was added to each well, and the absorbance at $405 \mathrm{~nm}$ was assessed and recorded every $150 \mathrm{~s}$ for a total of 40 data points, or until the concentration reached 0.2 absorbance units. The experimental value was determined using a standards curve that was prepared in parallel.

According to USP chapter $<85>$ bacterial endotoxins test (BET) [53], endotoxin limit was calculated as

$$
\text { Endotoxin limit }=\mathrm{K} / \mathrm{M} \text {, }
$$

with $\mathrm{K}$ being the threshold human pyrogenic dose per $\mathrm{kg}$ of body weight to be administered parenterally $(=5 \mathrm{EU} / \mathrm{kg})$ and $\mathrm{M}$ the maximum recommended bolus dose to be administered by $\mathrm{kg}$ of body weight. In this study, M equaled to $1 \mathrm{~mL} / 10 \mathrm{~kg}$ (estimate $4-5$ months old minipig body weight), leading to an endotoxin limit of $50 \mathrm{EU} / \mathrm{mL}$.

\subsection{In Vivo Study Design}

Two volumes of the test item were administered to assess the influence of the injection volume on injection site tolerability. A volume of $0.2 \mathrm{~mL}$ was considered the lowest amount to be manually filled into a $1 \mathrm{~mL}$ syringe with sufficient precision. A volume of $1 \mathrm{~mL}$ was set as the highest injectable volume, using the same injection device.

\subsubsection{Injection Site Selection}

The study was performed in 8 female Göttingen SPF minipigs purchased from Ellegaard Göttingen Minipigs A/S (Dalmose, Denmark). The age of the animals ranged from 4 to 5 months old, with a body weight of ca. $10 \mathrm{~kg}$ at arrival. The plica inguinalis was selected as the subcutaneous injection site because of known similarities with human skin in terms of thickness and the lack of panniculus carnosus, resulting in similar mechanical constraints $[23,54,55]$. Injection sites were tattooed one week before dosing as displayed in Figure 6.

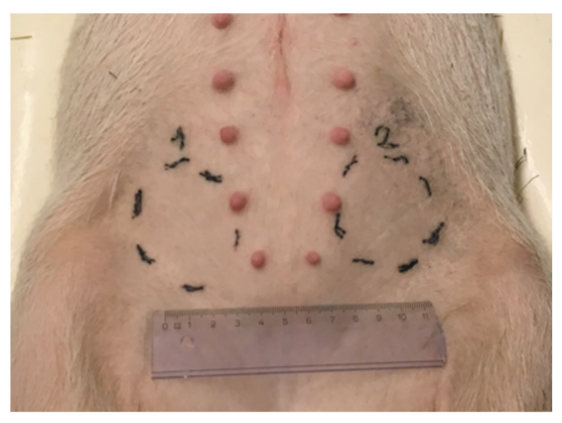

Figure 6. Marking of injection sites in the plica inguinalis of a minipig.

Animals were randomized in 2 groups of 4 animals:

- Group 1: $0.2 \mathrm{~mL}$ of test item (Animals \#1 to \#4);

- Group 2: $1 \mathrm{~mL}$ of test item (Animals \#5 to \#8).

To limit inter-animal variability, each animal received two injections of the same dose, at different flow rates:

- Site 1: target $1 \mathrm{~mL} / \mathrm{min}$ injection flow rate; 
- $\quad$ Site 2: target $10 \mathrm{~mL} / \mathrm{min}$ injection flow rate.

The animals were sacrificed at either $72 \mathrm{~h}$ (first two animals from each group) or $240 \mathrm{~h}$ (last two animals from each group) post-injection, and injection sites were recovered for further analysis.

\subsubsection{Injection of the Test Item}

The test item was supplied as ready-to-use. Samples were removed from the fridge and kept at room temperature the day before dosing to ensure that test item had completely thawed before injection (DMSO melting point $=+18-19{ }^{\circ} \mathrm{C}$ ). Animals were injected under general anesthesia with intramuscular ketamine $(6.25 \mathrm{mg} / \mathrm{kg}$ of $50 \mathrm{mg} / \mathrm{mL})$ and midazolam $(1.25 \mathrm{mg} / \mathrm{kg}$ of $5 \mathrm{mg} / \mathrm{mL})$ to maximize the consistency and reproducibility of injections, ketamine and midazolam being a common cocktail used as premedication of Göttingen minipigs. The test item was injected subcutaneously using a $1 \mathrm{~mL}$ Luer Lock Soft-Ject syringe (Henke Sass Wolf GmbH, Tuttlingen, Germany) equipped with a 21G 5/8" needle (BD Microlance, Becton Dickinson, Franklin Lakes, NJ, USA). The skin was pinched, and the full length of the needle was inserted with an angle between $45^{\circ}$ and $90^{\circ}$. Injection duration was recorded using a timer to calculate the experimental injection flow rate at each injection site. After each injection, the needle was left under the skin for $5 \mathrm{~s}$ before removal to minimize leakage of the product. On the day of necropsy, the animals were examined externally and then anaesthetized by an intramuscular injection (about $0.3 \mathrm{~mL} / \mathrm{kg}$ ), with a mixture of Zoletil 50 Vet. (Virbac S.A., Carros, France), $20 \mathrm{mg}$ xylazine/mL (6.25 mL), $100 \mathrm{mg}$ ketamine/mL (1.25 mL) and $10 \mathrm{mg}$ butorphanol/mL (2.5 mL). The animals were sacrificed by exsanguination and the injection sites explanted for histopathology analysis.

\subsection{Assessment of Loco-Regional Skin Tolerance}

Macroscopic observations were performed daily on unanesthetized animals laying on their backs, allowing a scoring of the injection sites. Loco-regional reactions, in particular hematoma, erythema, swelling such as oedema (soft swelling) or induration (hard swelling), scab, wound and scar, were recorded. Palpation was only allowed beyond $24 \mathrm{~h}$ postinjection to avoid interferences with the depot formation. On the day of dosing, the observations were recorded before and immediately after the injection.

\subsection{Ultrasound Imaging}

Ultrasound imaging was performed using a LOGIQ E9 (GE Healthcare, Chicago, IL, USA) with an ML6-15 transducer in B-mode at a frequency ranging from 13 to $15 \mathrm{MHz}$. Scanning was performed both pre- and post-injection, and then subsequently at $24 \mathrm{~h}$, $48 \mathrm{~h}, 72 \mathrm{~h}, 144 \mathrm{~h}$ and $240 \mathrm{~h}$ post-injection. Non-sedated animals were scanned from $24 \mathrm{~h}$ post-injection until study termination. Imaging was performed along the sagittal and transverse planes to allow for measurements of the depot. Measurements were collected using Horos $^{\mathrm{TM}}$ v3.3.6 software (Horos Project, New York, NY, USA). Depot volume was estimated using the ellipsoid volume formula:

$$
\mathrm{V}_{\text {depot }}=\pi / 6 \times \text { length } \times \text { width } \times \text { height, }
$$

Swelling degree (\%) was also determined using the formula:

$$
\text { Swelling degree }=\left(\mathrm{V}_{\text {depot }}-\mathrm{V}_{\text {injected }}\right) / \mathrm{V}_{\text {injected }} \times 100 \% \text {, }
$$

Findings were interpreted by two independent experts in ultrasound imaging.

\subsection{Histopathologic Evaluation}

Injection sites (depots and surrounding tissues) were entirely explanted at either $72 \mathrm{~h}$ or $240 \mathrm{~h}$ post-injection and prepared for histological processing. Skin samples were fixed in $10 \%$ buffered formalin, embedded in paraffin and cut at a nominal thickness of approximately $5 \mu \mathrm{m}$, stained with Hematoxylin and Eosin (H\&E) and then examined under a 
light microscope. Histological alterations were graded using a 5-level scale (minimal, mild, moderate, marked and severe).

\subsection{Statistical Treatment}

All data are reported as a mean with standard deviation. Statistical significance of the different data sets $(p<\alpha=0.05)$ was also investigated. Unpaired t-test and one-way analysis of variance (one-way ANOVA) were used for mean data comparison of injectabilities and ultrasound measurements comparison, respectively. Statistical treatment was performed using XLSTAT software (Addinsoft, Bordeaux, France).

\section{Conclusions}

This in vivo study in Göttingen minipigs allowed the demonstration of the locoregional safety of a test item based on ISFD $\mathrm{BEPO}^{\circledR}$ technology when injected subcutaneously at different flow rates and volumes. Injection site tolerability of the depot was evaluated by macroscopic and histopathological examination of the injection sites. Ultrasound imaging was also performed to support macroscopic observations and allow longitudinal depot measurements. Together, these experiments showed an acceptable loco-regional response to the injected polymeric test item, designed to be an extreme case study (i.e., a vehicle of very high viscosity and slow degradation kinetics), following low as well as high injection flow rates. The formation of a well-circumscribed subcutaneous nodule was observed along with a typical FBR for all injections. The scoring of the injection site reactions was volume-dependent and no cases of treatment-emergent adverse events were reported, ruling out any matter of concern from a histopathological perspective. It can thus be considered that the ISFD PEG-PDLLA based-product is well tolerated when injected subcutaneously at volumes ranging from $0.2 \mathrm{~mL}$ to $1 \mathrm{~mL}$ and injection flow rates up to $8 \mathrm{~mL} / \mathrm{min}$.

Based on the loco-regional tolerance data noted in the Göttingen minipigs, a humanrelevant animal model for subcutaneous administration, we consider the ISFD BEPO ${ }^{\circledR}$ technology likely to be safe in human patients.

Supplementary Materials: The following are available online at https:/ / www.mdpi.com/article/10 $.3390 /$ ijms22179250/s1.

Author Contributions: Conceptualization, C.P.; methodology, C.P., A.-P.T., J.D. and A.L.-N.; formal analysis, C.P.; investigation, C.P.; resources, C.P.; writing-original draft preparation, C.P.; writing-review and editing, J.D., J.R., C.R. and A.L.-N.; visualization, C.P.; supervision, A.L.-N.; project administration, A.-P.T. All authors have read and agreed to the published version of the manuscript.

Funding: This research was funded by MedinCell S.A. (Jacou, France).

Institutional Review Board Statement: The study was conducted according to the guidelines of the Declaration of Helsinki and approved by the Institutional Ethics Committee of CitoxLab Scantox A/S (protocol code 78251 approved on 12 February 2018).

Data Availability Statement: The data presented in this study are available on request from the corresponding author. The data are not publicly available due to commercial restrictions.

Acknowledgments: We thank Ulrik Westrup (Westrup Vet. Consulting, Lygby, Denmark) for ultrasound data acquisition and analysis as well as Loic Longeart (Loic Longeart Toxicologic Pathology, Vouvray, France), Marc Janier (Service of Nuclear Medicine of Hospices Civils de Lyon, Lyon, France) and Patrice Ravel (Cancer Research Institute of Montpellier, Montpellier, France) for their respective expertise in histopathology, imaging and statistics. The authors would also like to thank the Research Applied to Development Unit from MedinCell S.A., as well as Sophie Lelamer and Thibaut Deramoudt from the Preclinical Department and Simon Frydrych from the Development Department.

Conflicts of Interest: This work was supported by MedinCell S.A. (Jacou, France). The sponsor collaborated for the study design, data analysis and interpretation, as well as article writing. Authors 
one, two, four, five and six are employees and shareholders of MedinCell S.A. Author three is consultant and shareholder of MedinCell S.A.

\section{References}

1. Hoffman, A.S. The origins and evolution of "controlled" drug delivery systems. J. Control. Release 2008, 132, 153-163. [CrossRef]

2. Dash, A.K.; Cudworth, G.C., 2nd. Therapeutic applications of implantable drug delivery systems. J. Pharmacol. Toxicol. Methods 1998, 40,1-12. [CrossRef]

3. Kleiner, L.W.; Wright, J.C.; Wang, Y. Evolution of implantable and insertable drug delivery systems. J. Control. Release 2014, 181, 1-10. [CrossRef]

4. Martín del Valle, E.M.; Galán, M.A.; Carbonell, R.G. Drug Delivery Technologies: The Way Forward in the New Decade. Ind. Eng. Chem. Res. 2009, 48, 2475-2486. [CrossRef]

5. Kempe, S.; Mader, K. In situ forming implants-An attractive formulation principle for parenteral depot formulations. J. Control. Release 2012, 161, 668-679. [CrossRef] [PubMed]

6. Hatefi, A.; Amsden, B. Biodegradable injectable in situ forming drug delivery systems. J. Control. Release 2002, 80, 9-28. [CrossRef]

7. Potta, T.; Chun, C.; Song, S.C. Chemically crosslinkable thermosensitive polyphosphazene gels as injectable materials for biomedical applications. Biomaterials 2009, 30, 6178-6192. [CrossRef] [PubMed]

8. de Jong, S.J.; De Smedt, S.C.; Demeester, J.; van Nostrum, C.F.; Kettenes-van den Bosch, J.J.; Hennink, W.E. Biodegradable hydrogels based on stereocomplex formation between lactic acid oligomers grafted to dextran. J. Control. Release 2001, 72, 47-56. [CrossRef]

9. Vintiloiu, A.; Leroux, J.C. Organogels and their use in drug delivery-A review. J. Control. Release 2008, 125, 179-192. [CrossRef]

10. Thakur, R.R.; McMillan, H.L.; Jones, D.S. Solvent induced phase inversion-based in situ forming controlled release drug delivery implants. J. Control. Release 2014, 176, 8-23. [CrossRef]

11. Shah, N.H.; Railkar, A.S.; Chen, F.C.; Tarantino, R.; Kumar, S.; Murjani, M.; Palmer, D.; Infeld, M.H.; Malick, A.W. A biodegradable injectable implant for delivering micro and macromolecules using poly (lactic-co-glycolic) acid (PLGA) copolymers. J. Control. Release 1993, 27, 139-147. [CrossRef]

12. Parent, M.; Nouvel, C.; Koerber, M.; Sapin, A.; Maincent, P.; Boudier, A. PLGA in situ implants formed by phase inversion: Critical physicochemical parameters to modulate drug release. J. Control. Release 2013, 172, 292-304. [CrossRef]

13. Gold, R.; Rieckmann, P.; Chang, P.; Abdalla, J.; Group, P.S. The long-term safety and tolerability of high-dose interferon beta-1a in relapsing-remitting multiple sclerosis: 4-year data from the PRISMS study. Eur. J. Neurol. 2005, 12, 649-656. [CrossRef] [PubMed]

14. Paquette, S.M.; Dawit, H.; Hickey, M.B.; Merisko-Liversidge, E.; Almarsson, O.; Deaver, D.R. Long-acting atypical antipsychotics: Characterization of the local tissue response. Pharm. Res. 2014, 31, 2065-2077. [CrossRef] [PubMed]

15. Praestmark, K.A.; Jensen, C.B.; Stallknecht, B.; Madsen, N.B.; Kildegaard, J. Skin blood perfusion and cellular response to insertion of insulin pen needles with different diameters. J. Diabetes Sci. Technol. 2014, 8, 752-759. [CrossRef] [PubMed]

16. Thomsen, M.; Rasmussen, C.H.; Refsgaard, H.H.; Pedersen, K.M.; Kirk, R.K.; Poulsen, M.; Feidenhans'l, R. Spatial distribution of soluble insulin in pig subcutaneous tissue: Effect of needle length, injection speed and injected volume. Eur. J. Pharm. Sci. 2015, 79, 96-101. [CrossRef]

17. Chan, H. Effects of injection duration on site-pain intensity and bruising associated with subcutaneous heparin. J. Adv. Nurs. 2001, 35, 882-892. [CrossRef]

18. Kim, H.; Park, H.; Lee, S.J. Effective method for drug injection into subcutaneous tissue. Sci. Rep. 2017, 7, 9613. [CrossRef]

19. Doughty, D.V.; Clawson, C.Z.; Lambert, W.; Subramony, J.A. Understanding Subcutaneous Tissue Pressure for Engineering Injection Devices for Large-Volume Protein Delivery. J. Pharm. Sci. 2016, 105, 2105-2113. [CrossRef]

20. Gaudriault, G. EP3257498B1, Biodegradable Drug Delivery Compositions; MedinCell SA: Jacou, France, 2011.

21. Roberge, C.; Cros, J.M.; Serindoux, J.; Cagnon, M.E.; Samuel, R.; Vrlinic, T.; Berto, P.; Rech, A.; Richard, J.; Lopez-Noriega, A. $\mathrm{BEPO}(\mathrm{R})$ : Bioresorbable diblock mPEG-PDLLA and triblock PDLLA-PEG-PDLLA based in situ forming depots with flexible drug delivery kinetics modulation. J. Control. Release 2020, 319, 416-427. [CrossRef]

22. Leconet, W.; Liu, H.; Guo, M.; Le Lamer-Dechamps, S.; Molinier, C.; Kim, S.; Vrlinic, T.; Oster, M.; Liu, F.; Navarro, V.; et al. Anti-PSMA/CD3 Bispecific Antibody Delivery and Antitumor Activity Using a Polymeric Depot Formulation. Mol. Cancer Ther. 2018, 17, 1927-1940. [CrossRef] [PubMed]

23. Richter, W.F.; Bhansali, S.G.; Morris, M.E. Mechanistic determinants of biotherapeutics absorption following SC administration. AAPS J. 2012, 14, 559-570. [CrossRef] [PubMed]

24. Wei, J.C.J.; Edwards, G.A.; Martin, D.J.; Huang, H.; Crichton, M.L.; Kendall, M.A.F. Allometric scaling of skin thickness, elasticity, viscoelasticity to mass for micro-medical device translation: From mice, rats, rabbits, pigs to humans. Sci. Rep. 2017, 7, 15885. [CrossRef] [PubMed]

25. Berteau, C.; Filipe-Santos, O.; Wang, T.; Rojas, H.E.; Granger, C.; Schwarzenbach, F. Evaluation of the impact of viscosity, injection volume, and injection flow rate on subcutaneous injection tolerance. Med. Devices 2015, 8, 473-484. [CrossRef]

26. Turner, P.V.; Brabb, T.; Pekow, C.; Vasbinder, M.A. Administration of substances to laboratory animals: Routes of administration and factors to consider. J. Am. Assoc. Lab. Anim. Sci. 2011, 50, 600-613.

27. Zaybak, A.; Khorshid, L. A study on the effect of the duration of subcutaneous heparin injection on bruising and pain. J. Clin. Nurs. 2008, 17, 378-385. [CrossRef] 
28. Jockel, J.P.; Roebrock, P.; Shergold, O.A. Insulin depot formation in subcutaneoue tissue. J. Diabetes Sci. Technol. 2013, 7, 227-237. [CrossRef]

29. Watt, R.P.; Khatri, H.; Dibble, A.R.G. Injectability as a function of viscosity and dosing materials for subcutaneous administration Int. J. Pharm. 2019, 554, 376-386. [CrossRef]

30. Solorio, L.; Babin, B.M.; Patel, R.B.; Mach, J.; Azar, N.; Exner, A.A. Noninvasive characterization of in situ forming implants using diagnostic ultrasound. J. Control. Release 2010, 143, 183-190. [CrossRef]

31. Cui, H.; Shao, J.; Wang, Y.; Zhang, P.; Chen, X.; Wei, Y. PLA-PEG-PLA and its electroactive tetraaniline copolymer as multiinteractive injectable hydrogels for tissue engineering. Biomacromolecules 2013, 14, 1904-1912. [CrossRef]

32. Sharma, D.; Singh, J. Long-term glycemic control and prevention of diabetes complications in vivo using oleic acid-graftedchitosanzinc-insulin complexes incorporated in thermosensitive copolymer. J. Control. Release 2020, 323, 161-178. [CrossRef] [PubMed]

33. Kim, T.Y.; Kim, D.W.; Chung, J.Y.; Shin, S.G.; Kim, S.C.; Heo, D.S.; Kim, N.K.; Bang, Y.J. Phase I and pharmacokinetic study of Genexol-PM, a cremophor-free, polymeric micelle-formulated paclitaxel, in patients with advanced malignancies. Clin. Cancer Res. 2004, 10, 3708-3716. [CrossRef]

34. Kim, S.C.; Kim, D.W.; Shim, Y.H.; Bang, J.S.; Oh, H.S.; Wan Kim, S.; Seo, M.H. In vivo evaluation of polymeric micellar paclitaxel formulation: Toxicity and efficacy. J. Control. Release 2001, 72, 191-202. [CrossRef]

35. Schoenhammer, K.; Boisclair, J.; Schuetz, H.; Petersen, H.; Goepferich, A. Biocompatibility of an injectable in situ forming depot for peptide delivery. J. Pharm. Sci. 2010, 99, 4390-4399. [CrossRef] [PubMed]

36. Dong, S.; Wang, S.; Zheng, C.; Liang, W.; Huang, Y. An in situ-forming, solid lipid/PLGA hybrid implant for long-acting antipsychotics. Soft Matter 2011, 7, 5873-5878. [CrossRef]

37. Braeckman, J.; Michielsen, D. Efficacy and tolerability of 1- and 3-month leuprorelin acetate depot formulations (Eligard ${ }^{\circledR} /$ DepoEligard ${ }^{\circledR}$ ) for advanced prostate cancer in daily practice: A Belgian prospective non-interventional study. Arch. Med. Sci. 2014, 10, 477-483. [CrossRef] [PubMed]

38. Ohlmann, C.H.; Gross-Langenhoff, M. Efficacy and Tolerability of Leuprorelin Acetate (Eligard(R)) in Daily Practice in Germany: Pooled Data from 2 Prospective, Non-Interventional Studies with 3- or 6-Month Depot Formulations in Patients with Advanced Prostate Cancer. Urol. Int. 2018, 100, 66-71. [CrossRef]

39. Royals, M.A.; Fujita, S.M.; Yewey, G.L.; Rodriguez, J.; Schultheiss, P.C.; Dunn, R.L. Biocompatibility of a biodegradable in situ forming implant system in rhesus monkeys. J. Biomed. Mater. Res. 1999, 45, 231-239. [CrossRef]

40. Kranz, H.; Brazeau, G.A.; Napaporn, J.; Martin, R.L.; Millard, W.; Bodmeier, R. Myotoxicity studies of injectable biodegradable in-situ forming drug delivery systems. Int. J. Pharm. 2001, 212, 11-18. [CrossRef]

41. Zheng, Y.; Tesar, D.B.; Benincosa, L.; Birnbock, H.; Boswell, C.A.; Bumbaca, D.; Cowan, K.J.; Danilenko, D.M.; Daugherty, A.L.; Fielder, P.J.; et al. Minipig as a potential translatable model for monoclonal antibody pharmacokinetics after intravenous and subcutaneous administration. MAbs 2012, 4, 243-255. [CrossRef]

42. Patel, R.B.; Solorio, L.; Wu, H.; Krupka, T.; Exner, A.A. Effect of injection site on in situ implant formation and drug release in vivo. J. Control. Release 2010, 147, 350-358. [CrossRef]

43. Solorio, L.; Olear, A.M.; Zhou, H.; Beiswenger, A.C.; Exner, A.A. Effect of cargo properties on in situ forming implant behavior determined by noninvasive ultrasound imaging. Drug Deliv. Transl. Res. 2012, 2, 45-55. [CrossRef] [PubMed]

44. Graham, P.D.; Brodbeck, K.J.; McHugh, A.J. Phase inversion dynamics of PLGA solutions related to drug delivery. J. Control. Release 1999, 58, 233-245. [CrossRef]

45. Liu, H.; Venkatraman, S.S. Cosolvent effects on the drug release and depot swelling in injectable in situ depot-forming systems. J. Pharm. Sci. 2012, 101, 1783-1793. [CrossRef]

46. Bode, C.; Kranz, H.; Siepmann, F.; Siepmann, J. In-situ forming PLGA implants for intraocular dexamethasone delivery. Int. J. Pharm. 2018, 548, 337-348. [CrossRef] [PubMed]

47. Anderson, J.M. Biological Responses to Materials. Annu. Rev. Mater. Res. 2001, 31, 81-110. [CrossRef]

48. Anderson, J.M.; Rodriguez, A.; Chang, D.T. Foreign body reaction to biomaterials. Semin. Immunol. 2008, 20, 86-100. [CrossRef]

49. Fournier, E.; Passirani, C.; Montero-Menei, C.N.; Benoit, J.P. Biocompatibility of implantable synthetic polymeric drug carriers: Focus on brain biocompatibility. Biomaterials 2003, 24, 3311-3331. [CrossRef]

50. Nyska, A.; Schiffenbauer, Y.S.; Brami, C.T.; Maronpot, R.R.; Ramot, Y. Histopathology of biodegradable polymers: Challenges in interpretation and the use of a novel compact MRI for biocompatibility evaluation. Polym. Adv. Technol. 2014, 25, 461-467. [CrossRef]

51. Rousselle, S.D.; Ramot, Y.; Nyska, A.; Jackson, N.D. Pathology of Bioabsorbable Implants in Preclinical Studies. Toxicol. Pathol. 2019, 47, 358-378. [CrossRef]

52. Kilkenny, C.; Browne, W.J.; Cuthill, I.C.; Emerson, M.; Altman, D.G. Improving bioscience research reporting: The ARRIVE guidelines for reporting animal research. PLoS Biol. 2010, 8, e1000412. [CrossRef] [PubMed]

53. Convention, U.S.P. Bacterial Endotoxins Test Stage 6 Harmonization. In USP 35-NF 30; United States Pharmacopeial Convention, Inc.: Rockville, MD, USA, 2012.

54. Rose, E.H.; Vistnes, L.M.; Ksander, G.A. The panniculus carnosus in the domestic pig. Plast. Reconstr. Surg. 1977, 59, 94-97. [CrossRef] [PubMed] 
55. Allmendinger, A.; Mueller, R.; Schwarb, E.; Chipperfield, M.; Huwyler, J.; Mahler, H.C.; Fischer, S. Measuring tissue backpressure-in vivo injection forces during subcutaneous injection. Pharm. Res. 2015, 32, 2229-2240. [CrossRef] [PubMed] 